\section{Propagation of Sciadopitys verticillata (Thunb.) Sieb. \& Zucc. by Stem Cuttings and Properties of Its Latex-like Sap}

\author{
David I. Yates, Brandi L. Earp, and Foster Levy ${ }^{1}$ \\ Department of Biological Sciences, East Tennessee State University, Box \\ 70703, Johnson City, TN 37614
}

\section{Elaine S. Walker University, Johnson City, TN 37614 \\ Additional index words. Japanese umbrella pine, antimicrobial, rooting}

James H. Quillen Veterans Affairs Medical Center, Mountain Home, TN 37684; and Division of Infectious Diseases, Department of Internal Medicine, James H. Quillen College of Medicine, East Tennessee State

\begin{abstract}
To improve the success of vegetative propagation of Sciadopitys verticillata, stem cuttings were subjected to three treatments designed to minimize the accumulation of a latex-like sap at the cut ends of stems. A 24-hour soak in water before a hormone dip significantly enhanced rooting success and root mass. The water soak pretreatment was more beneficial to hardwood cuttings compared with softwood cuttings. Cuttings from shade-grown source trees showed the highest rooting success, but source tree age, height, and place of origin were not important factors. The water-insoluble latex-like sap had strong antibacterial activity against 3 of 11 bacterial species tested, but activity was not related to bacterial Gram reaction or the bacterial natural environment. In contrast, pine resins and latexes from selected angiosperms showed no antibacterial activity. The antibacterial component of the Sciadopitys latex-like sap was heat stable and therefore probably not protein based.
\end{abstract}

Japanese umbrella pines [Sciadopitys verticillata (Thunb.) Sieb. \& Zucc.] are highly desirable landscape trees because of their pleasing full conical shape, green color throughout the year, relatively slow growth rate for a conifer, and absence of troublesome pests or pathogens. Propagation of $S$. verticillata has been difficult and limited in scope because of poor seed germination and slow growth of resultant seedlings (Rudolf and Owston, 2003; Waxman, 1957, 1960). Although it has been nearly three decades since Waxman (1978) described techniques that resulted in an extremely high success rate in rooting stem cuttings of $S$. verticillata, more recent studies have failed to replicate Waxman's findings (Douds et al., 1995; Halladin, 1991). Hence, the species is still considered difficult to propagate and remains a specialty

\footnotetext{
Received for publication 31 May 2006. Accepted for publication 28 July 2006.

This material is the result of work supported with resources and the use of facilities at the James $\mathrm{H}$. Quillen Veterans Affairs Medical Center.

We thank Barbara Ownley for cultures of plant pathogens, John Laffan for cultures of soil bacteria, Chris Liu for translation, owners of source trees for permission to take cuttings, and Cecilia McIntosh, Dhirendra Kumar, and an anonymous reviewer for insightful comments.

${ }^{1}$ To whom reprint requests should be addressed; e-mail levyf@etsu.edu
}

plant because of limited availability and high cost (Goodhart, 2000).

$S$. verticillata differs from all other conifers in its production of a viscous, milky colored, latex-like, nonresinous sap (Langenheim, 2003). The latex is produced in laticifer ducts and is secreted from wounds such as those induced by stem cuttings. When exposed to air, the latex quickly hardens and the resultant seal of the wound is hypothesized to provide protection from pathogens (Farrell et al., 1991; Shukla and Krishna Murti, 1971). However, there have been suggestions that this latex-like substance plays a primary role in the inhibition of adventitious roots (Waxman, 1978).

Some reports on optimal techniques for vegetative propagation of $S$. verticillata suggested that the efficiency of success in rooting stem cuttings could be improved by soaking the cut end of the stem in water for either 2 to $3 \mathrm{~h}$ (Tu and Sheng, 1980) or 24 to $48 \mathrm{~h}$ before hormone treatment and planting (Flemer, 1961; Waxman, 1978). The water soak pretreatment was intended to ameliorate the hypothesized inhibitory effects on rooting of the latex-like sap by channeling the latex away from the cut end of the stem. However, the success rate appeared to depend strongly upon the source tree. Moreover, more recent studies have failed to detect beneficial effects of a water soak pretreatment and have reported far more modest rooting success rates
(Douds et al., 1995; Halladin, 1991). A goal of this study was to test rigorously the effects of water soak pretreatments on rooting success of hardwood and softwood stem cuttings. In addition, experiments were designed to examine the influences on rooting of 1) different source trees, 2) source trees of different heights and ages, 3) source trees growing under different sunlight conditions, and 4) softwood and hardwood cuttings.

Evidence from other species suggests the natural function of plant latexes and resins may be as defenses against pests and pathogens (Dussourd and Eisner, 1987; Farrell et al., 1991; Lokvam et al., 2000; Rukachaisirikul et al., 2005). Observations that $S$. verticillata is relatively disease and pest free, and the wood is resistant to decay, suggest $S$. verticillata may produce natural compounds that inhibit microbial growth. Based on these observations, we postulated that the latex of $S$. verticillata may possess antimicrobial activity that would be suitable for broader applications. Consequently, another goal of the study was to test crude latex extracts for in vitro antimicrobial activity against a suite of bacterial species that occupy diverse habitats.

\section{Materials and Methods}

Stem cuttings. Hardwood (March) and softwood (June) cuttings were taken from six landscape trees growing at various sites in three counties (Carter, Unicoi, Washington) in northeast Tennessee. Source trees included two each from the small, medium, and tall height classes (Table 1). None of these trees were known to be derived from the same source material (Table 1). Stem cuttings were taken during the morning on overcast days to minimize drying during transport and preparation. The number of cuttings per tree varied from 40 to 100 per season, depending upon the tree size. Cuttings averaged $15 \mathrm{~cm}$ in length and had approximate average diameters of $0.5 \mathrm{~cm}$. Immediately before pretreatment, cuttings were laterally scored $3 \mathrm{~cm}$ from the basal end.

All cuttings were dipped in a 1:5 (by volume) dilution of Dip-N-Grow hormone solution (a.i. of 1.0\% indole-3-butyric acid and $0.5 \%$ 1-napthaleneaceticacid) for $1 \mathrm{~min}$ combined with either no other treatment (control) or preceded by one of three pretreatments: a fresh basal cut was made followed by soaking in water for $24 \mathrm{~h}$ (water soak), a fresh basal cut was made underwater followed by soaking in water for $24 \mathrm{~h}$ (water cut and soak), or a fresh basal cut was made followed by soaking $24 \mathrm{~h}$ in a $0.5 \%$ solution of the detergent Tween-20 (detergent soak). These treatments were designed to minimize coagulation of latex at the cut ends of stems. The detergent soak was included in an attempt to solubilize the latex, an approach that was based on reports that plant latexes may be lipid soluble (Langenheim, 2003). After treatments, cuttings were placed to a depth of $7 \mathrm{~cm}$ in soilless media composed of 1 peatmoss : 1 perlite (by volume) in tree trays 
Table 1. Characteristics of source trees used for stem cuttings.

\begin{tabular}{lclclcc}
\hline & & & & \multicolumn{2}{c}{$\begin{array}{c}\text { No. of cuttings } \\
\text { per treatment } \\
\text { per season }\end{array}$} & Source $^{\text {z }}$ \\
\hline Tree & Height $(\mathrm{m})$ & $\begin{array}{c}\text { Height } \\
\text { class }\end{array}$ & Age $(\mathrm{y})$ & Light & Oregon \\
MM & 1 & Small & 15 & Sun & 10 & Oregon \\
HC & 2 & Small & 12 & Shade & 15 & Tennessee \\
FL & 3 & Medium & 20 & Sun & 10 & Oregon \\
GM & 4 & Medium & 15 & Sun & 10 & New Jersey \\
VA & 8 & Tall & $<30$ & Shade & 25 & Japan \\
\hline
\end{tabular}

${ }^{\mathrm{z}}$ All currently growing in northeast Tennessee.

with cells $10 \mathrm{~cm}$ deep $\times 5 \mathrm{~cm}$ square. Cuttings were placed under intermittent mist of $10 \mathrm{~s}$ on and $3 \mathrm{~min}$ off during daylight hours in a greenhouse with temperatures of 23 to $30{ }^{\circ} \mathrm{C}$ and year-round $50 \%$ shade cloth.

Small numbers of cuttings were visually inspected monthly for rooting. Rooting success was scored 6 months after planting, at which time cuttings were gently separated from the media by hand, visually inspected, and assigned to one of the following five groups: heavily rooted (more than five roots longer than $3 \mathrm{~cm}$ ), lightly rooted (five or fewer roots, all shorter than $3 \mathrm{~cm}$ ), callused, viable (green needles but no roots or callus), or dead.

Latex preparation. Latex sap for antibiotic trials was collected from the "LN" and "VA" trees (Table 1). Fresh stem cuttings $\approx 20 \mathrm{~cm}$ in length were obtained by cutting branches with pruners that were surface sterilized in a $10 \%$ solution of chlorine bleach for $5 \mathrm{~min}$. Before sap extraction, the stem ends of cuttings were surface sterilized in a $10 \%$ solution of chlorine bleach for $5 \mathrm{~min}$, rinsed four times in sterile distilled water, patted dry with a sterile towel, and then allowed to air dry for $\approx 5 \mathrm{~min}$. The basal ends of stems were then freshly cut with a sterile scalpel and the sap was collected into sterile $1.5-\mathrm{mL}$ microfuge tubes containing $600 \mu \mathrm{L}$ sterile $0.15 \% \mathrm{NaCl}$. Sap was "milked" into the $\mathrm{NaCl}$ for $\approx 1$ min with the aid of hemostats. The sap suspension was vortexed for $5 \mathrm{~s}$ before use.

Bacterial samples. Samples of frozen cultures of test bacteria were spread on Petri plates containing tryptic soy agar and incubated overnight at $37^{\circ} \mathrm{C}$. Colonies from these overnight cultures were suspended in $0.15 \% \mathrm{NaCl}$ to a density of $0.5 \mathrm{McF}$ arland equivalence turbidity visual standard $\left(\approx 10^{8}\right.$ cells $\left.\cdot \mathrm{mL}^{-1}\right)$. Bacterial suspensions were spread on Petri plates containing MuellerHinton agar to produce a bacterial lawn. Plates were incubated $20 \mathrm{~min}$ at $37^{\circ} \mathrm{C}$ before applying sap extracts. Bacteria subjected to testing included four plant commensals/ pathogens (Agrobacterium tumefaciens, Erwinia amylovora, Pseudomonas syringae, Xanthomonas sp.), two soil-inhabiting species of Bacillus (B. cereus, B. subtilis), and five human-associated commensals/pathogens (Escherichia coli, Moraxella catarrhalis, Neisseria cinerea, Staphylococcus aureus, S. epidermidis).

Each treatment, except treatment 2 listed here, consisted of three replicates of $5 \mu \mathrm{L}$ sap suspension gently pipetted onto plates with bacterial lawns. The following treatments were tested:

1. Control $(0.15 \% \mathrm{NaCl})$

2. Bleach control: a nonsterile pencil was surface sterilized as described earlier and touched three times to the media. This treatment was designed to show that the surface sterilization of wood was not inhibitory to the bacterial lawn.

3. Sap suspension at room temperature

4. Sap suspension heated to $65^{\circ} \mathrm{C}$ or $100^{\circ} \mathrm{C}$ for $10 \mathrm{~min}$, then cooled to room temperature

5. Supernatant of sap suspension after centrifugation for $45 \mathrm{~s}$ at $14,000 \mathrm{rpm}$

6. Concentrated latex suspension obtained by resuspending the pellet from centrifugation in treatment 5 in $50 \mu \mathrm{L}$ $0.15 \% \mathrm{NaCl}$

Sap applications were allowed to absorb onto the plates for $15 \mathrm{~min}$ at room temperature, followed by overnight incubation at $37{ }^{\circ} \mathrm{C}$ and visual inspection for bacterial inhibition zones.

To determine whether latex from $S$. verticillata differed in its antimicrobial properties relative to pine resins or other latex-like plant compounds, antibacterial activity trials, similar to those used with latex from $S$. verticillata, were conducted on resins from three species of pine (Pinus nigra, P. strobus, $P$. virginiana) and on latex sap extracts from the following four angiosperm species: Mandevilla sanderi (Apocynaceae), Ficus benjamina (Moraceae), Euphorbia milii (Euphorbiaceae), and E. pulcherrima (Euphorbiaceae). The angiosperm species were chosen to represent major latex-producing genera from distantly related plant families.

Statistical analysis. The effects of season, treatment, and light environment of source tree on rooting were compared using threefactor analysis of variance (ANOVA) in which the response variables were tree-specific arcsine transformed percentages of heavily rooted, lightly rooted, and callused cuttings. Percentages of heavily and lightly rooted cuttings were combined after a preliminary analysis showed patterns of significance that were nearly identical. A separate three-factor ANOVA was conducted on the arcsine transformed percent of cuttings with callus formation. Means were compared using LSD a posteriori tests.

\section{Results}

Stem cuttings. The combined percentage of heavily and lightly rooted cuttings showed highly significant season, treatment, and light environment main effects (Table 2). The percentage of rooting was significantly higher for hardwood cuttings (rooting means: hardwood, $33.5 \%$; softwood, $22.8 \%$ ), a pattern observed within all treatments (Fig. 1). Roots ranged from short, single, unbranched primary roots to well-developed, long $(>15$ $\mathrm{cm}$ ), branched root systems (Fig. 2). The size of the tree from which cuttings were taken had no significant effect on rooting efficiency (means: small, 40\%; medium, 29\%; tall, $34 \%$; heterogeneity $\chi^{2}=2.58, d f=2, P=$ 0.28; Fig. 3). A similar absence of an effect would be observed if age was substituted for height because age and height were strongly correlated $(r=0.90, t=4.08, d f=4, P=0.02)$.

Within each cutting season, the two 24-h water soak pretreatments yielded significantly more rooted cuttings compared with untreated controls and cuttings soaked in detergent (Fig. 1). Thus, the benefit of a water soak pretreatment was negated by adding detergent to the water. None of the two-way or three-way interactions involving treatment effects were significant, which indicates the treatment differences were consistent over cutting seasons and source tree environments (Table 2). There was a significant environment $\times$ season interaction, in which rooting was higher in hardwood cuttings from shadegrown trees (mean rooting, 49.7\%) compared with either softwood cuttings from shadegrown trees (mean rooting, 25.4\%) or softwood and hardwood cuttings from sun-grown trees (rooting means, $21.7 \%$ and $25.4 \%$ respectively). Hardwood cuttings from the two shade-grown trees (MM and GM in Fig. 3) showed $86 \%$ greater rooting efficiency than cuttings from any of the four sun-grown trees. In contrast, softwood cuttings from shadegrown trees showed only a $25.0 \%$ increase in rooting compared with cuttings from sungrown trees.

Light environment of the source tree was the only main effect with a significant influence on callus formation (Table 3). Cuttings from sun-grown trees were much more likely to form callus compared with cuttings from shade-grown trees (callus means: sun grown, $41.3 \%$; shade grown, $5.9 \%$ ). Considering only unrooted cuttings, $86 \%$ from sungrown trees formed callus compared with $14 \%$ from shade-grown trees. Cuttings from shade-grown trees that failed to root tended to die rather than produce callus.

Physical and functional properties of latex extracts. Latex extracted from $S$. verticillata formed a suspension in water but it dissolved in $90 \%$ ethanol. The aqueous suspension had a $\mathrm{pH}$ of 5.8 and an absorbance maximum at $420 \mathrm{~nm}$. There was no apparent relationship between bacterial inhibition and natural environment of the bacteria. Antibacterial activity was detected against 6 of 11 bacterial species representing Gram-positive soil-associated and human-associated species and Gram-negative human-associated species (Table 4). None of the four plant-associated species was inhibited (Table 4). The antibacterial component of the $S$. verticillata 
Table 2. Three-way analysis of variance (season $\times$ treatment $\times$ light environment of source tree) for percentage rooting (heavily + lightly) of stem cuttings.

\begin{tabular}{lllrc}
\hline Source & $d f$ & MS & $F$ & $P$ \\
Season & 1 & 0.26 & 39.02 & $<0.0001$ \\
Treatment & 3 & 0.23 & 34.33 & $<0.0001$ \\
Environment & 1 & 0.25 & 36.51 & $<0.0001$ \\
Season $\times$ treatment & 3 & 0.009 & 1.34 & 0.28 \\
Season $\times$ environment & 1 & 0.15 & 21.96 & $<0.0001$ \\
Treatment $\times$ environment & 3 & 0.002 & 0.32 & 0.81 \\
Season $\times$ treatment $\times$ environment & 3 & 0.003 & 0.48 & 0.70 \\
\hline
\end{tabular}

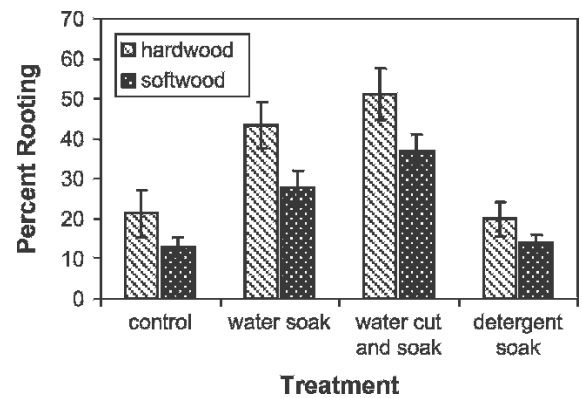

Fig. 1. Effects of treatments on rooting of hardwood and softwood stem cuttings of Sciadopitys verticillata. Error bars represent SEM.

extract was heat stable and associated with the relatively insoluble latex, as evidenced by the absence of antimicrobial activity in the supernatant derived from centrifugation of the latex suspension (Table 4). Moreover, complete antibacterial activity was maintained against $S$. aureus in 100:1 dilutions of the unconcentrated extracts, but activity was diminished at this dilution against $M$. catarrhalis and $N$. cinerea (data not shown). In contrast, none of the extracts from the three pine species or the four latex-producing angiosperms had antibacterial activity against any of the bacterial species (data not shown).

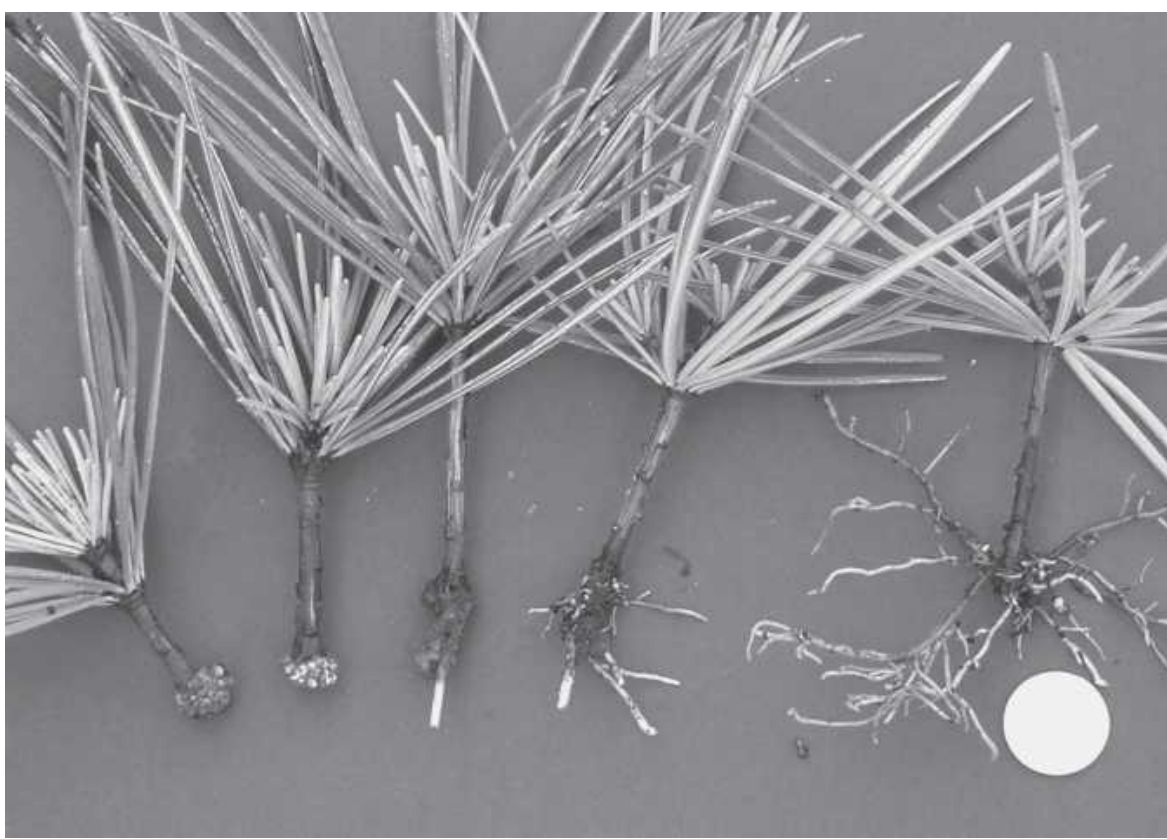

Fig. 2. Stem cuttings showing callus formation (two at left), light rooting (two in center), and heavy rooting (right). Quarter coin at lower right for scale.
Using source trees growing in the northeastern United States, Flemer (1961) confirmed Waxman's (1960) observation that with an appropriate water soak pretreatment, rooting success in excess of $80 \%$ could be attained using hardwood cuttings taken in early spring (late February to mid March), but Flemer's results were based on only 10 cuttings per treatment. A similarly high rooting success rate $(86 \%-96 \%$, depending upon hormone treatment) was reported for cuttings taken from a single large tree in the Jiangxi province in China and planted into a 7 sand : 3 humus (by volume) mix in the shade and humidity of a tree canopy ( $\mathrm{Tu}$ and Sheng, 1980). Unfortunately, reports of rooting success in more recent studies have contradicted the finding of a beneficial effect of a water soak pretreatment. In Oregon, Halladin (1991) also used early spring cuttings, but his rooting success rates of $40 \%$ to $80 \%$ after 6 months were substantially lower than those of the earlier reports. Halladin noted that rooting success differed from year to year, and he observed no benefit to a water soak pretreatment. Similarly, Douds et al. (1995) followed Waxman's water soak pretreatment protocol but after 7 months they obtained only $17 \%$ rooting, a rate that was increased to $50 \%$ with the aid of mycorrhizae.

Our results clearly confirmed the beneficial effect of a water soak pretreatment, but the magnitude of rooting success was more modest than those of the early reports. Moreover, despite size, age, place of origin, and environmental differences among our source trees, our cuttings showed substantially less variation among source trees compared with previous reports. For example, the range in mean rooting success rates among our trees varied by $\approx 30 \%$, compared with $100 \%$ observed by Waxman (1978). Although we sampled from only two shade-grown trees, much of the difference in rooting success was associated with the light environment of the source tree- that is, rooting was significantly higher in cuttings from shade-grown trees. To examine factors that may explain the shadegrown source tree effect, we noted that terminal branches on shade-grown trees differed from those on sun-grown trees in that they tended to be thinner in diameter, more flexible and less lignified, and they exuded less latex when cut (Fig. 4).

The apparent morphological and physiological differences associated with sun and shade light environments may have been a consequence of less copious latex, or it could have been mediated by lesser lignification, either directly or as an indicator of a physiological condition associated with juvenility. Although tree maturation effects are manifested along a stem axis gradient (Burdon et al., 2004), bulking of cuttings combines stems from various height regions of each tree and thus mixes stems at different maturation states. Because cuttings from more mature stems tend to root less effectively, the bulking procedure we used may have obscured potential height and age effects. In loblolly and Monterey pines, rooting 


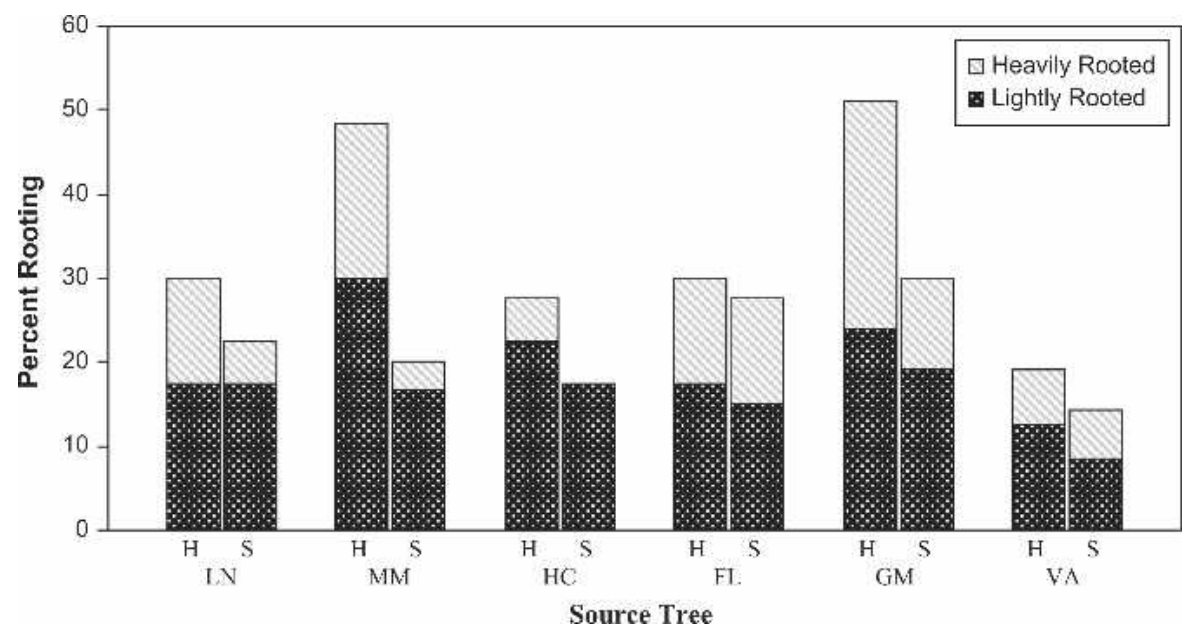

Fig. 3. Rooting of hardwood $(\mathrm{H})$ and softwood $(\mathrm{S})$ stem cuttings from different source trees. Source trees ordered by increasing height from left to right (on a nonlinear scale). MM and GM were shade-grown source trees; all others were sun grown.

Table 3. Three-way analysis of variance (season $\times$ treatment $\times$ light environment of source tree) for percentage of cuttings forming callus.

\begin{tabular}{lcccc}
\hline Source & $d f$ & MS & $F$ & $P$ \\
\hline Season & 1 & 0.03 & 1.62 & 0.21 \\
Treatment & 3 & 0.04 & 2.59 & 0.07 \\
Environment & 1 & 1.48 & 87.19 & $<0.0001$ \\
Season $\times$ treatment & 3 & 0.001 & 0.05 & 0.98 \\
Season $\times$ environment & 1 & 0.02 & 1.32 & 0.26 \\
Treatment $\times$ environment & 3 & 0.05 & 2.84 & 0.053 \\
Season $\times$ treatment $\times$ & 3 & 0.001 & 0.03 & 0.99 \\
environment & & & &
\end{tabular}

Table 4. Antibacterial activity of latex sap extracts of Sciadopitys verticillata subjected to different treatments and tested against various bacterial species.

\begin{tabular}{|c|c|c|c|c|c|c|c|}
\hline \multirow[b]{2}{*}{ Bacterial species } & \multirow[b]{2}{*}{ Gram } & \multirow[b]{2}{*}{$\mathrm{NaCl}$} & \multicolumn{5}{|c|}{ Extract treatment } \\
\hline & & & $\begin{array}{c}\text { Room } \\
\text { temperature }\end{array}$ & $65^{\circ} \mathrm{C}$ & $100^{\circ} \mathrm{C}$ & Supernatant & $\begin{array}{c}\text { Concentrated } \\
\text { latex }\end{array}$ \\
\hline \multicolumn{8}{|l|}{ Plant associated } \\
\hline Agrobacterium tumefaciens & - & $\mathrm{X}$ & $\mathrm{X}$ & $\mathrm{X}$ & na & $\mathrm{X}$ & $\mathrm{X}$ \\
\hline Erwinia amylovora & - & $\mathrm{X}$ & $\mathrm{X}$ & $\mathrm{X}$ & na & $\mathrm{X}$ & $\mathrm{X}$ \\
\hline Pseudomonas syringae & - & $\mathrm{X}$ & $\mathrm{X}$ & $\mathrm{X}$ & na & $\mathrm{X}$ & $\mathrm{X}$ \\
\hline Xanthomonas sp. & - & $\mathrm{X}$ & $\mathrm{X}$ & $\mathrm{X}$ & na & $\mathrm{X}$ & $\mathrm{X}$ \\
\hline \multicolumn{8}{|l|}{ Soil associated } \\
\hline Bacillus cereus & + & $\mathrm{X}$ & $\sqrt{ }$ & $\sqrt{ }$ & na & $\mathrm{X}$ & $\sqrt{ }$ \\
\hline B. subtilis & + & $\mathrm{X}$ & $\sqrt{ }$ & $\sqrt{ }$ & na & $\mathrm{X}$ & $\sqrt{ }$ \\
\hline \multicolumn{8}{|l|}{ Human associated } \\
\hline Escherichia coli & - & $\mathrm{X}$ & $\mathrm{X}$ & $\mathrm{X}$ & na & $\mathrm{X}$ & $\mathrm{X}$ \\
\hline Moraxella catarrhalis & - & $\mathrm{X}$ & $\sqrt{ }$ & $\sqrt{ }$ & $\sqrt{ }$ & $\mathrm{X}$ & $\sqrt{ }$ \\
\hline Neisseria cinerea & - & $\mathrm{X}$ & $\sqrt{ }$ & $\sqrt{ }$ & $\sqrt{ }$ & $\mathrm{X}$ & $\sqrt{ }$ \\
\hline Staphylococcus aureus & + & $\mathrm{X}$ & $\sqrt{ }$ & $\sqrt{ }$ & na & $\mathrm{X}$ & $\sqrt{ }$ \\
\hline S. epidermidis & + & $\mathrm{X}$ & $\sqrt{ }$ & $\sqrt{ }$ & na & $\mathrm{X}$ & $\sqrt{ }$ \\
\hline
\end{tabular}

$\sqrt{ }$, bacterial inhibition; $\mathrm{X}$, no inhibition; na, not assessed.

success can be enhanced by maintaining cutting stock as hedges (Burdon et al., 2004; Libby et al., 1972). Hedging prolongs the juvenile state and thin-diameter stems. Similarly, in $S$. verticillata, rooting success was highest in thin-diameter cuttings from shade-grown source trees. Perhaps the effects of shade-induced etiolation are analogous to those of juvenility.

An inverse correlation between the percentage of rooted cuttings and the quantity of latex exuded from the cut end of cuttings led Waxman (1978) to hypothesize that the beneficial effect of the water soak is conferred by draining and channeling the latex away from the region of the cut end of the stem.

Antimicrobial activity. Antimicrobial activity of the $S$. verticillata sap extracts was restricted to the latex as evidenced by the presence of activity in the latex-enriched fraction after centrifugation of the sap suspension and the lack of activity associated with the supernatant. The stability of activity at 65 to $100{ }^{\circ} \mathrm{C}$ suggests the antibacterial component is not a protein, a result that was not unexpected given the complex nature of plant latexes (Shukla and Krishna Murti, 1971) (Fig. 5). The observation that only some bacterial species were inhibited and that none of the other plant latexes were antibacterial demonstrated the inhibitory effect had a specific physiological rather than general physical basis (i.e., it is unlikely that the latex had a suffocating-type effect when pipetted over the bacterial lawn). None of the pine resins or other plant latexes we tested had antibacterial activity, a finding that was consistent with a report showing no antibacterial activity of milkweed (Asclepias syriaca, Asclepiadaceae) latex extracts (McCay and Mahlberg, 1973). In contrast, latex from the trunk of Clusia grandiflora (Clusiaceae) inhibited growth of honeybee bacterial pathogens from the genus Paenibacillus (Lokvam et al., 2000), and xanthones isolated from the stem latex of Garcinia scortechinii were active against methicillin-resistant S. aureus (Rukachaisirikul et al., 2005).

The active antibacterial compounds in latex from $S$. verticillata were selective in the bacteria that were inhibited, but this selectivity was not related to Gram reaction. Therefore, the antibacterial activity is probably not related to differences in bacterial cell wall composition. Moreover, remarkably low titers of the latex showed antimicrobial activity. All bacterial species were exposed to a 1:12 dilution of the latex (approximate 50 $\mu \mathrm{L}$ latex was milked into $600 \mu \mathrm{L} \mathrm{NaCl}$ ), but depending upon the bacterial species, activity was maintained either completely or to a somewhat reduced extent when the initial suspension was further diluted 1:100 to give a final concentration 1200 times more dilute than the pure extract. Other plant latexes have been shown to play a role in plant defense (Dussourd and Eisner, 1987; Farrell et al., 1991; Lewinsohn, 1991). Thus, we may speculate that latex from $S$. verticillata has a protective function related to injury, and that a component of the protective function is to act as an antimicrobial agent. However, we have not demonstrated that pathogens of $S$. verticillata are inhibited in vivo. In fact, the bacterial species that were inhibited in this study were not plant pathogens, and the plant pathogens examined are not known to colonize or infect $S$. verticillata. Perhaps latex from $S$. verticillata may possess antifungal properties against fungi associated with wounds. Nevertheless, the latex sap of S. verticillata appears to inhibit adventitious root formation in stem cuttings and it displays 


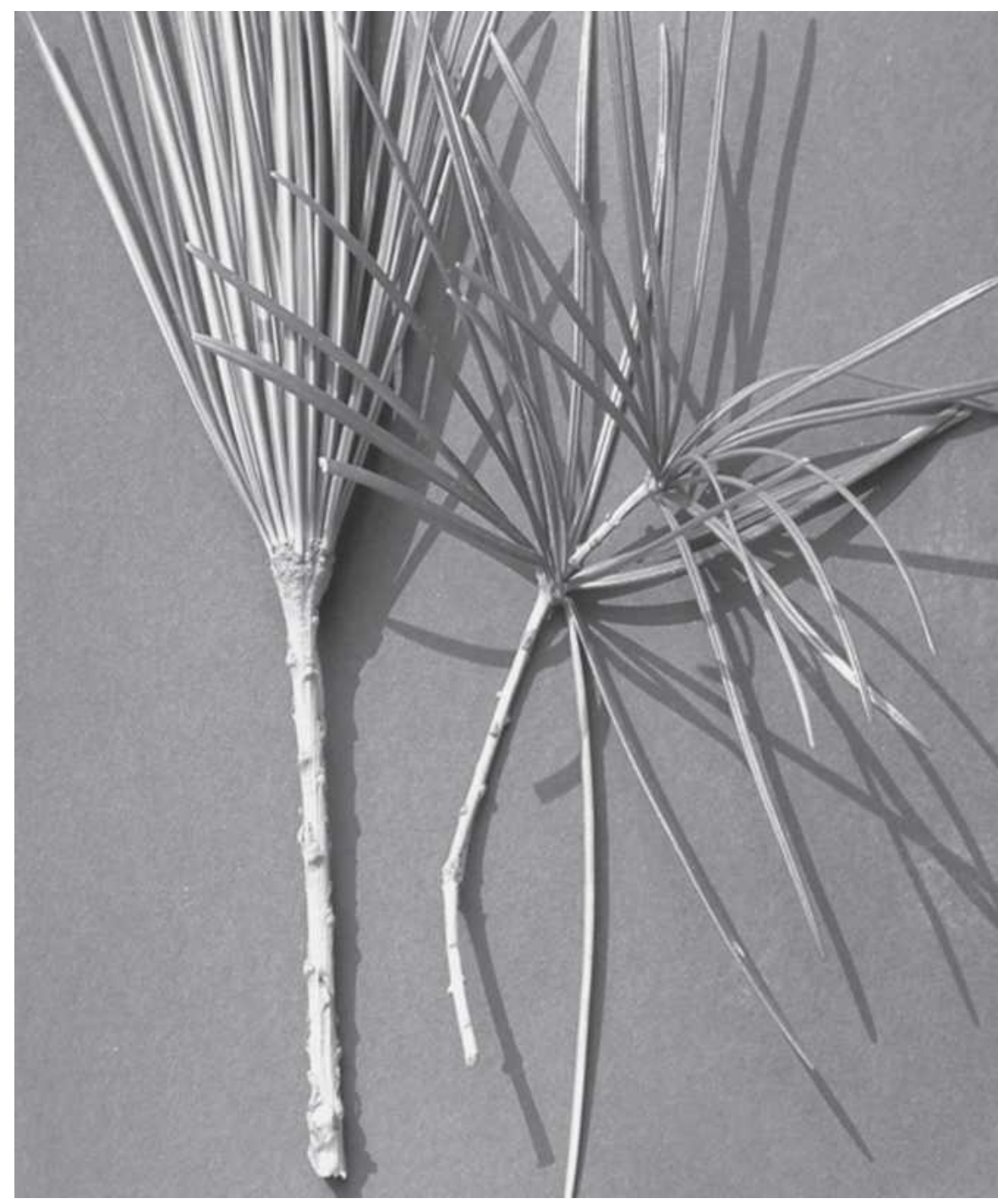

Fig. 4. Cuttings from sun-grown (left) and shade-grown (right) trees. Note the larger diameter and firmness of the sun-grown stem.

potent antibiotic activity against several bacterial species.

\section{Literature Cited}

Burdon, R.D., R.P. Kibblewhite, J.C.F. Walker, R.A. Megraw, R. Evans, and D.J. Cown. 2004 Concept, orthogonal to corewood versus outerwood, with special reference to Pinus radiato and P. taeda. Forest Sci. 50:399-415.

Douds, D.D. Jr., G. Becard, P.E. Pfeffer, L.W. Doner, T.J. Dymant, and W.M. Kayser. 1995. Effect of vesicular-arbuscular mycorrhizal fungi on rooting of Sciadopitys verticillata Sieb. \& Zucc. cuttings. HortScience 30:133134.

Dussourd, D.E. and T. Eisner. 1987. Vein-cutting behavior: Insect counterploy to the latex defense of plants. Science 237:898-901.
Farrell, B.D., D.E. Dussourd, and C. Mitter. 1991. Escalation of plant defense: Do latex and resin canals spur plant diversification? Amer. Naturalist 138:881-900.

Flemer, W., III. 1961. Further experiences in rooting Sciadopitys verticillata cuttings. Comb. Proc. Intl. Plant Prop. Soc. 11:104-106.

Goodhart, F.W. 2000. Propagation aspects of Sciadopitys verticillata and Sequoiadendron giganteum 'Hazel Smith'. Comb. Proc. Intl. Plant Prop. Soc. 50:222-226.

Halladin, P. 1991. Sciadopitys verticillata. Amer. Nurseryman 174:73.

Langenheim, J.H. 2003. Plant resins. Timber Press, Portland, Ore.

Lewinsohn, T.M. 1991. The geographical distribution of plant latex. Chemoecology 2:64-68.

Libby, W.J., A.G. Brown, and J.M. Fielding. 1972. Effects of hedging radiata pine on production,

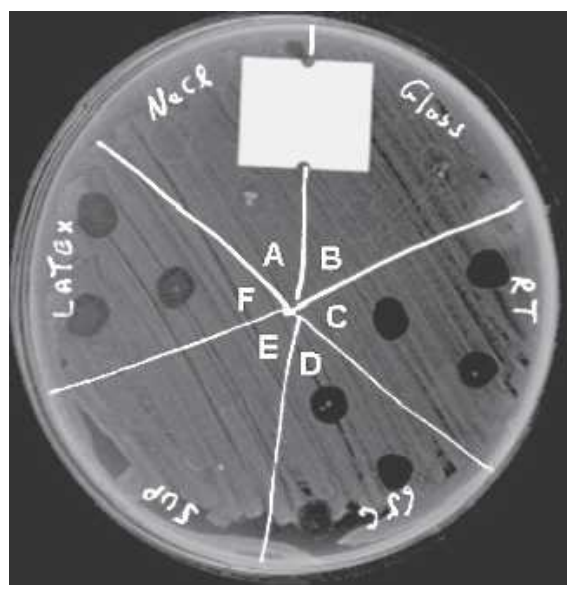

Fig. 5. Petri plate showing assay for antimicrobial activity of Sciadopitys verticillata latex extracts on a lawn of Staphylococcus aureus. In each plate sector, except $\mathrm{B}$, three $5-\mu \mathrm{L}$ drops were applied. Sectors: A, NaCl control; B, control, surface-sterilized pencil applied to plate; C, extract at room temperature; D, extract heated to $65{ }^{\circ} \mathrm{C}$ then cooled before application; E, extract centrifuged and supernatant applied; F, concentrated latex applied after resuspension of latex pellet.

rooting and early growth of cuttings. N.Z.J. For. Sci. 2:263-283.

Lokvam, J., J.F. Braddock, P.B. Reichardt, and T.P. Clausen. 2000. Two polyisoprenylated benzophenones from the trunk latex of Clusia grandiflora (Clusiaceae). Phytochemistry 55:29-34.

McCay, S. and P. Mahlberg. 1973. Study of antibacterial activity and bacteriology of latex from Asclepias syriaca L. Antimicrob. Agents Chemother. 3:247-253.

Rudolf, P.O. and P.W. Owston. 2003. Woody plant seed manual. USDA Forest Service, www. nsl.fs.fed.us/wpsm/Sciadopitys.pdf.

Rukachaisirikul, V., P. Phainuphong, Y. Sukpondma, and W.C. Taylor. 2005. Antibacterial cagedtetraprenylated xanthones from the stem bark of Garcinia scortechinii. Plant Med. 71: $165-170$.

Shukla, O.P. and C.R. Krishna Murti. 1971. The biochemistry of plant latex. J. Sci. Ind. Res. (India) 30:640-662

Tu, Y.G. and J.Y. Sheng. 1980. Zhongguo lin ye ke xue yan jiu yuan ke ji qing bao yan jiu suo [Experiments on the planting of Sciadopitys verticillata cuttings]. Lin ye ke ji tong xun [For Tech. Newsltr.] 5:5-6.

Waxman, S. 1957. Effects of daylength on the germination of Sciadopitys verticillata. Comb. Proc. Intl. Plant Prop. Soc. 7:71-72.

Waxman, S. 1960. Propagation of Sciadopitys verticillata. Comb. Proc. Intl. Plant Prop. Soc. 10:178-183.

Waxman, S. 1978. Propagation of umbrella pine (Sciadopitys verticillata)-clonal differences in root initiation. Comb. Proc. Intl. Plant Prop. Soc. 28:546-550 